\title{
Review Paper on CFD Modelling and Simulation of slurry through Centrifugal Pump
}

\author{
Authors \\ Vishwatesh Raj ${ }^{1}$, P.N. Ulhe ${ }^{2}$ \\ ${ }^{1,2}$ Department of Mechanical Engineering, SSBT'S College of Engineering and Technology, Bambhori,
}

Jalgaon (M.S.)

\begin{abstract}
The pumps or pumping systems for slurry transport will depend not only on the flow, suction conditions, head required, location, method of installation, as for any pump application. A centrifugal pump is designed to handle clear liquids. However slurries are to be transported the conventional centrifugal pump has to be modified to handle solid liquid mixtures. As the design of centrifugal pump involve a large number of interdependent variables, several other alternative design are possible for same duty.
\end{abstract}

\section{INTRODUCTION :}

A pump is a machine used to move liquid through a piping system and to raise the pressure of the liquid. A pump can be further defined as a machine that uses several energy transformations to increase the pressure of a liquid.

\subsection{Types of Pumps}

\subsubsection{Rotary Pump}

Rotary pump is used to move heavy or very viscous fluids. These employ mechanical means such as gear, cam and screw to move the liquid.

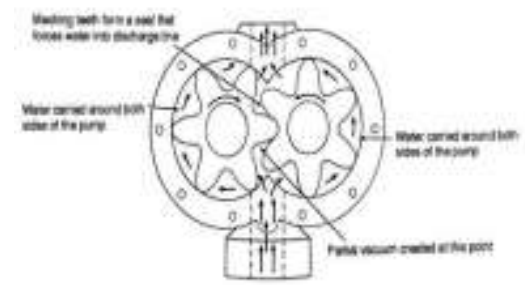

\subsubsection{Reciprocating Pumps}

In reciprocating pumps the mechanical energy is converted into hydraulic energy by sucking the liquid into a cylinder in which a piston is reciprocating(moving backwards and forwards)which exerts the thrust on the liquid and increases its hydraulic energy (pressure energy),the pump is known as reciprocating pump. Reciprocating pumps are used where a precise amount of liquid is required to be delivered, also where the delivery pressure required is higher than that can be achieved with other types. Figure 1.2 shows line diagram of reciprocating pump.

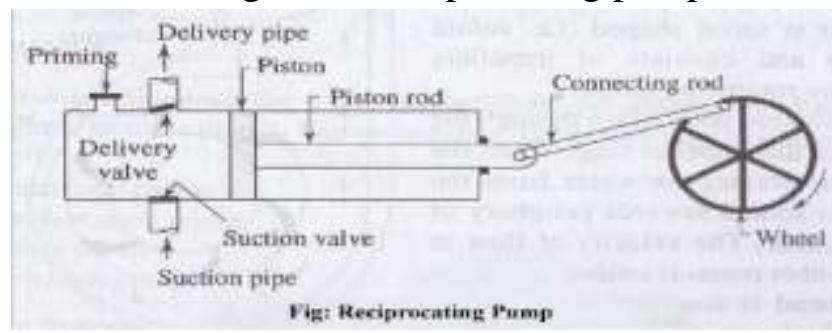

\subsubsection{Centrifugal Pump}

It is the rotodynamic machine. By rotating action develop the pressure able to lifting of liquid lower level to higher level. Centrifugal pump is explained with the following headings:

\subsubsection{Working Principle of Centrifugal Pump}

Centrifugal pumps works on the basis of second law of Newton. Due to the rotation of the runner, called impeller the fluid at the inner radius moves to the outer radius \& gain the Centrifugal head. Suction is created at the inlet to the pump which is called the eye. Continuous lifting of fluid thus takes place from sump to the pump while passing through the impeller the fluid take the energy from vane sin pressure \& kinetic energy. A large amount of impeller outlet therefore made to convert the kinetic energy of fluid into pressure energy before the fluid enters the developing pipe. 


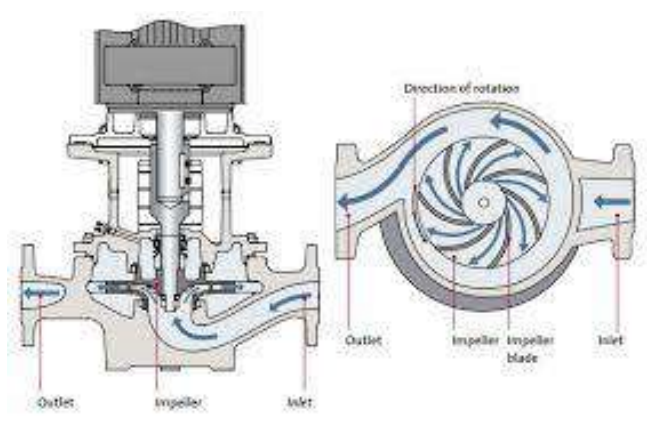

\subsection{Classification of Centrifugal Pump}

Based on their utility, design and Constructional features, centrifugal pumps can be classified with respect to the following characteristics.

\subsubsection{Number of Stage}

\section{(a) Single stage pump}

It has one impeller keyed to the shaft. This is generally horizontal but can be vertical also. It is usually low lift pump.

\section{(b) Multistage pump}

Multi Stage Centrifugal Pump:-It has two or more impellers keyed to a single shaft enclosed in the same casing. Pressure is built up in steps. The impeller is surrounded by guide vanes and the water is led through a by-pass channel from the outlet of one stage to the entrance of the next until it is finally discharged into a wide chamber from where it is pushed on to the delivery pipe. These pumps are used essentially for high working heads and the number of stages depends on the head required.

\subsubsection{Number of entrance to impeller}

a) Single entry or single suction pump: In a single suction pump liquid is admitted from a suction pipe on one side of impeller.

b) Double suction pump: In double suction pumps liquid enters from both sides of impeller. A double suction pump has an advantage that by this arrangement the axial thrust on the impeller is neutralized.
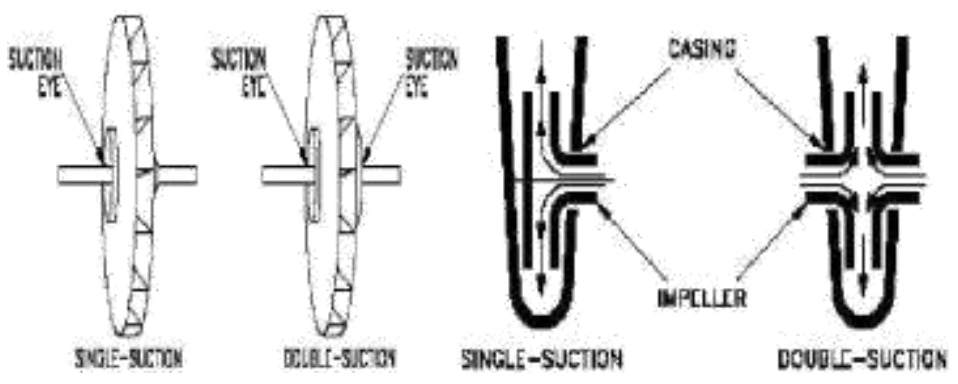

\subsubsection{Liquid handled}

Depending on the type and viscosity of liquid to be pumped, the pump may have a closed or open impeller.

a) Closed impeller: An ordinary centrifugal pump is equipped with a closed impeller in which the vanes are covered with shrouds on both sides. This type is meant to handle non-viscous liquid such as ordinary water, hot water, hot oils and chemicals like acids etc, material of the impeller should be selected according to the chemical properties of liquid used. For hot water at temperature exceeding 150 degree celcius cast steel impeller is recommended.

b) Semi open impeller: The impeller is provided with shroud on one side only. This pump is used for viscous liquid such as sewage; paper pulp etc, choice of material for manufacturer of impeller is influenced by chemical nature of liquid to be handled.

c) Open Impeller Pump: The impeller is not provided with any shroud. Such pumps are used in dredgers, and elsewhere for handling mixture of water, sand, clay etc, it is generally made of forged steel.
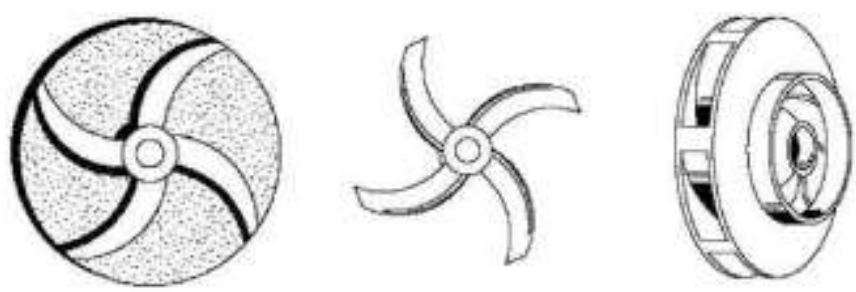

Fig- a) Semi-open impell b) Open impeller C) Closed impeller

\subsubsection{Working head}

a) Low lift Centrifugal pumps: Low lift centrifugal pumps are meant to work against heads up to $15 \mathrm{~m}$, Impeller is surrounded by a volute and there are no guide vanes.

b) Medium lift: Medium lift centrifugal pumps are used to build up heads as high as $40 \mathrm{~m}$. They are generally provided with guide vanes.

c) High lift: High lift centrifugal pumps are employed to deliver liquids at heads above $40 \mathrm{~m}$. High pumps are generally multistage pumps because single impeller cannot build up such a high pressure. 


\subsubsection{Types of casing}

Pump casing should be so designed as to minimize the loss of kinetic head through eddy formation etc. Efficiency of the pumps largely depends on the type of casing.

a) Volute casing: A casing operates on the principle of increasing the pressure energy in a free-vortex or spiral flow. In free-vortex, Angular momentum is constant.

So, $\quad M V R=C O N S \tan T$ and $\therefore R \propto 1 / V$.

Volute casing cross-section of the moving stream gradually increases from torque towards the discharging pipe. This increase in area results in a gradually decrease in velocity (kinetic energy) with corresponding increases in pressure. Most of the single stage pumps are built with volute casing.

b) Volute with vortex chamber: Vortex or whirl pool chamber: Annular space is provided between the volute and impeller. This arrangement arrests the formation of eddies and gives an improved performance.

c) Diffusion pumps: Impeller surrounded by a guide wheel consisting of a number of stationary vanes or diffuser providing outlets with crosssection gradually enlarging towards the periphery. Water emerging from impeller flow past the guide vanes and as the section across flow increases, velocity falls and pressure is build up. Angle of guide vanes at the entrance should coincide with the direction of absolute velocity of water at impeller outlet. This arrangement is employed in all multistage pumps.

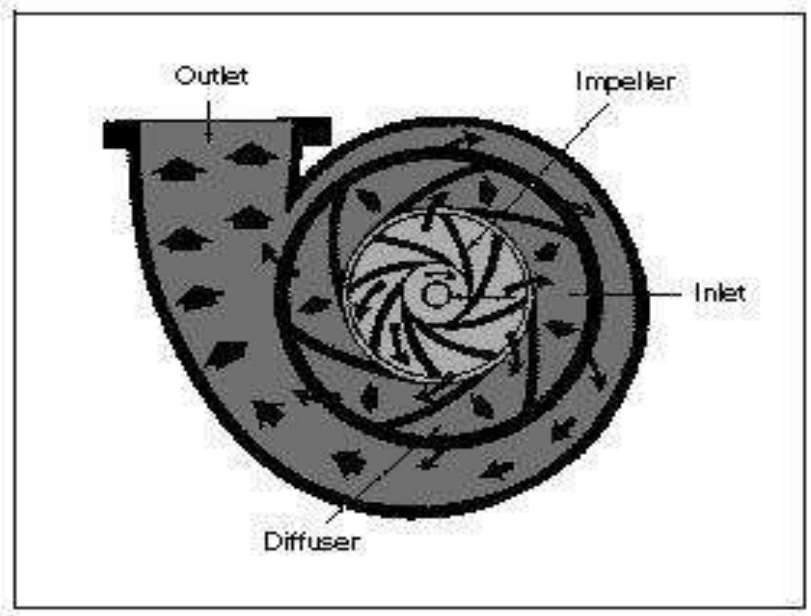

Fig- Diffusion pump
1.2.6 Relative direction of flow through impeller

a) Radial flow pump: It is that pump in which the liquid flows through the impeller in the radial direction only. Ordinarily all the Centrifugal pumps manufacture with radial flow impeller.

b) Mixed flow pump: In mixed flow pumps the liquids flows through the impeller axially as well as radially i.e. there is a combination of radial and axial flows. A mixed flow pump is just a modification of radial flow type in this respect that the former is capable of discharging a large quantity of liquid.

c) Axial flow pumps: In axial flow pumps the impeller is in the axial direction only. Axial flow pumps are usually designed to deliver very large quantities of liquid at relatively low heads. However, it is not justified to call axial flow pumps as centrifugal pumps because there is hardly any centrifugal action in their operation.

\subsubsection{Suction and Discharge Nozzle}

a) End suction/Top discharge - This pump is always of an overhung type and typically has lower NPSH because the liquid feeds directly into the impeller eye.

b) Top suction/Top discharge - This pump can either be an overhung type or between-bearing type but is always a radially split case pump.
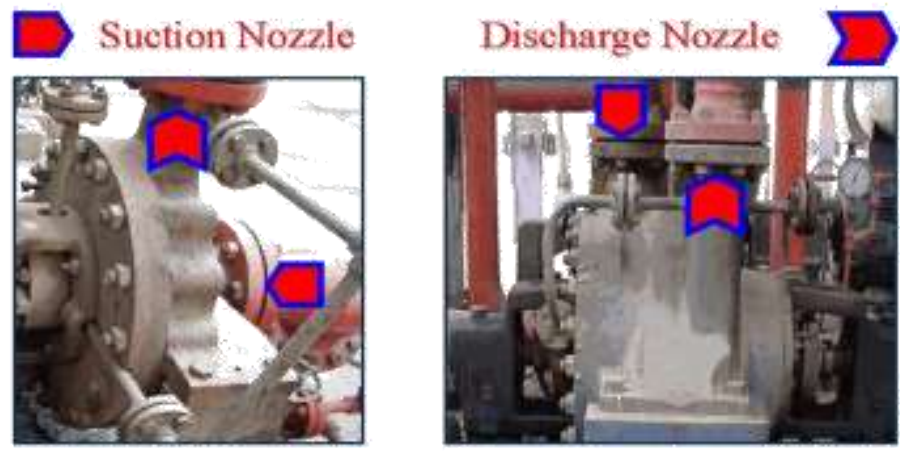

a) End suction/Top discharge

b) Top suction/Top discharge

Fig- Position of Suction \& discharge.

\subsubsection{Specific speed $(\mathbf{N})$}

Slow speed radial flow runner- 10 to $30 \mathrm{rpm}$

Normal speed radial flow impeller- 30 to $50 \mathrm{rpm}$

High speed radial flow impeller- 50 to $80 \mathrm{rpm}$

Mixed flow runner- 80 to $160 \mathrm{rpm}$

Axial flow runner- 110 to $150 \mathrm{rpm}$ 


\subsubsection{Position of impeller}

a) Horizontal impeller shaft pump

b) Vertical impeller shaft pump

The centrifugal pumps may be designed with either horizontal or vertical position of shaft, generally the pumps are provided with horizontal shaft. For deep wells and mines the pumps with vertical shaft are more suitable because the pumps with vertically disposed shaft occupy less space.
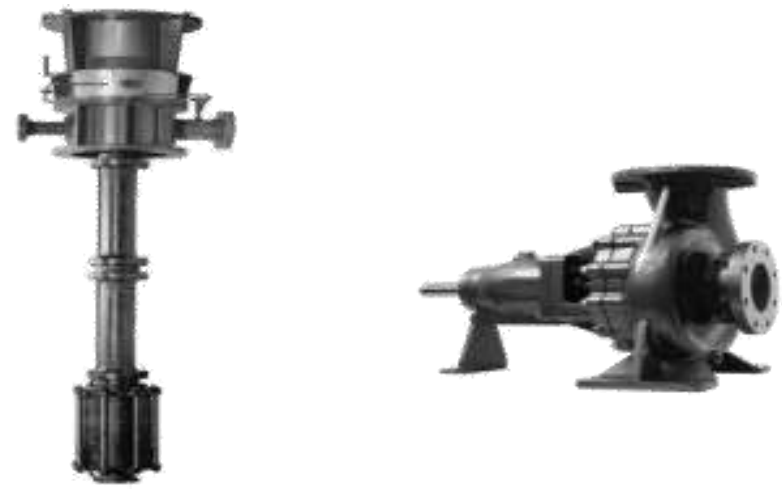

Fig- a) Horizontal shaft pump

b) Vertical shaft pump

\subsubsection{Outlet blade angle}

(a) Backward Blade: Outlet blade curves in a direction opposite to that of motion, \& the angle between the blade tip $\&$ the tangent to rotor at exit is below $90\left(\beta_{2}<90\right)$

(b) Radial Blade: Liquid leaves the blade with relative velocity in a radial direction \& angle $\beta_{2}=90$.

(c) Forward Blade: Outlet tip of blade curves in the direction of motion $\&$ the angle between blade tip \& the tangent to rotor at exit is obtuse $\left(\beta_{2}>90\right)$
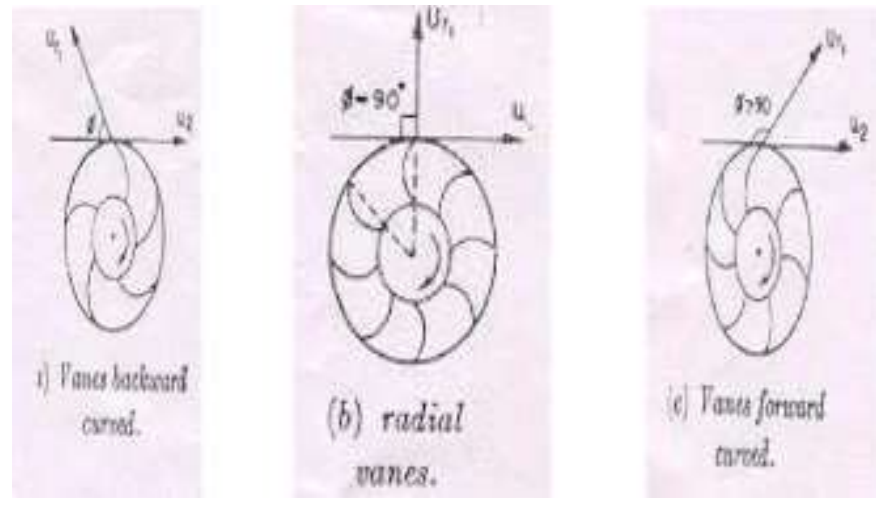

Fig- Outlet blade angle.

\subsection{Centrifugal Pump Applications}

Pumps are used wherever any quantity of liquid must be moved from one place to another. Pumps are found in such services as steam power plants; water supply plants; sewage; drainage or irrigation; oil refineries, chemical plants and steel mills; food processing factories and mines; dredging or jetting operations; hydraulic power services and almost every ship whether driven by diesel or steam engine. While these pumps have much in common, they are varied to meet special requirements and particular needs of each service.

- Petroleum Industry

- Chemical Industry

- Textile Industries

- Paper Industry

- Sewage and Sump Services

- Irrigation, Drainage and Flood Control

\subsection{Merits Of Centrifugal Slurry Pump}

i) Simplified design

ii) Easy installation

iii) Easy maintenance

iv) Lesser weight

v) Easy transportation of fluids.

\subsection{Centrifugal Pump For Slurry}

A conventional centrifugal pump is designed to handle clear liquids. However when slurries are to be transported the conventional centrifugal pump has to be modified to handle solid liquid mixtures. The modifications incorporated in the pump include enlargement of flow passages to accommodate bigger solid particles, robust impeller with smaller number of vanes, special seals and proper material of construction to ensure longer life. Slurry pumps are available in variety of materials of construction to best handle the abrasion, corrosion and impact requirements of nearly any solids handling application, replaceable liners are used in critical areas of wear to reduce the costs of parts replacement. The materials used have different properties to prevent wear and erosion to ensure longer working life as compared to conventional pumps used for clear liquids. These modifications increase the hydraulic losses in the pump and deteriorate the pump performance. The efficiency of a centrifugal slurry pump is considerably low as compared to a conventional pump. The performance characteristics of slurry pumps are also poor as 
compared to the conventional pumps. The deterioration in the performance could be attributed to the modifications incorporated to allow free flow of solid particles along with the liquid to be transported. The designers of slurry pumps have to take the following parameters into account while designing the slurry pumps:

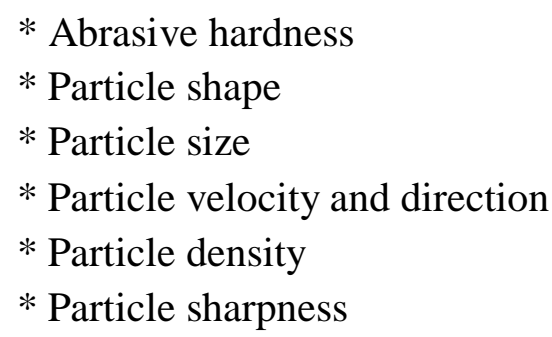

During the design of such pumps, the requirements of longer life and reliability is to be balanced by the constrained of high initial costs and efficiency. Nearly all slurry pumps have larger diameter impellers than units for pumping clear liquids, to enable heads and capacities to be met at reduced rotational speed. Low speed operation is one of the most important wear reducing features of a slurry pump A centrifugal slurry pump is designed to handle solid-liquid mixture and is normally a single stage, end suction type having radial or mixed flow configurations to facilitate the motions of solid particles Some compromises are made in order to provide an acceptable pump life. Table 1.1 shows the design features, benefits, and compromises of the slurry pump.

\subsection{Transportation of Slurry}

There has been a phenomenal growth in the demand of raw materials over the last few decades. This increase into drastic change in the existing demand has led techniques of mining, food processing, power suspende generation and other sectors where transportation of solids play a major role. Due to this change, there has been an increase in requirements in slurry transportation. A typical slurry transport system is shown in the figure 1.6. Pump plays a vital role in transportation of slurry; different types of pumps are available for slurry transportation, but centrifugal pumps are most widely used in slurry transportation applications due to the following reasons:-
Higher flow rates can be obtained.

Pulse free flow can be obtained.

\section{LITERATURE REVIEW}

Ward et al. (1999) investigated the hydraulic transportation of dense fly ash slurry using a stabilizing additive to prevent sedimentation of fly ash particles. But the addition of stabilizing additive increased the slurry viscosity for which a dispersing additive was to be used to solve the problem.

Eric dick et al. [2001] have used different methods of fluent code (Moving Reference frame, Mixing plane method \& sliding mesh technique) to predict the performance of centrifugal pump. They took two pumps, one of which has a low specific speed in 2-d form \& second one has medium specific speed \& doubly curved vanes. They found that head is a function of flow rate $\&$ found quite closer to the experimental results above nominal flow rates. Effect of pressure variation on the impeller flow is analysed. Finally, sliding mesh technique has been found to be the most effective technique, which also considers the fluid inertia effect on flow.

Jose' Gonza'lez et al. [2002] have studied the fluent code to predict the dynamic effects of unsteady fluid flow due to impeller-volute interaction in centrifugal pumps. Sliding mesh technique with $\mathrm{k}-\varepsilon$ turbulence model, time averaged Navier-Stokes equations on a commercial pump with backward curved blades are applied. They concluded that good agreement between the studied \& experimental results generated for static pressure, unsteady distribution \& dynamic forces at off-design operating conditions has been found.

Weidong Zhou et al. [2003] have predicted the off-design performance of two pumps with straight \& twisted blades respectively using CFD code CFX, with advanced mesh technology for complex geometries and $\mathrm{k}-\varepsilon$ turbulence model. It was found that twisted bladed pump had better efficiency amongst the two. Similarly, comparing the two pumps both with twisted blades of different sizes; it was found that $25 \%$ of the 
design flow rate, the flow pattern is almost same. At $35-40 \%$ of the design flow rate, the reverse flow arises and flow pattern changes.

Parida et al. (2003) using the flow and head loss characteristics of high concentration fly ashbottom ash mixture slurry carried out the pipeline design for hydraulic back-filling of coal mines by considering the effects of solids concentration, bottom ash fraction, pipe diameter and flow velocity. A design chart was formulated to determine the pipe size and design transport velocity for a given backfilling rate and given $\mathrm{H} / \mathrm{L}$ ratio i.e. length of vertical section of pipe $(\mathrm{m})$ to length of horizontal section of the pipe (m).

K M Guleren et al.[2004] demonstrated a simulated work on flow in centrifugal vane pump having five curved blades with nine diffuser vanes. The pump model is generated in gambit \& solid works \& flow is analysed by fluent software. Analysis done at 15 different flow rates produces unstable results due to stalled region effects. Also these results have good agreement with the experimental ones. The performance curve and flow instabilities are also predicted very well by the fluent. Pressure fluctuations around the impeller and diffuser were found to be dependent on flow rate. The fluctuation is particularly more at off-design conditions but more stable at the design flow rate.

J.M. Sankovic et al. [2004] demonstrated the results of the initial phase of obtaining experimental measurements throughout a rotary pump. Measurements in the volute exit/diffuser section were obtained at different pump speeds. Over the range of operating conditions tested, various flow phenomena were noted Reynolds shear stress measurements showed regions of significant stress levels that warrant further investigation.

G. R. Addie et al. [2005]worked on a 3 vane pump with $0.3 \mathrm{~m}$ diameter impeller \& open shroud with the help of unique model called "Viscosity correction method" to find the effect of properties of slurries on the performance \& wear of pump. Different results obtained here point out the strong influence of the rheological behaviour on the choice of pump size and the power requirement. Also with the same method, the efficiency of nonNewtonian fluid was measured in a reasonable way but head reduction was under-estimated. For the underground fluid stated above, the method gives good results of viscosity at BEP flow rate but head and efficiency results were overestimated.

\section{John S.Anagnostopaupolos et al. [2006]}

demonstrated a 3-d turbulent flow simulation of centrifugal pumps solving RANS equation with control volume approach on Cartesian grid. A no. of controllable design variables is taken under consideration so as to optimize the geometry of impeller. Hydraulic efficiency, flow analysis \& performances are calculated. Also the flow analysis vs. various design parameters is also drawn. The results are found to be in agreement with the experimental results. So, the use of design variables in impeller geometry along with grid generation algorithm constitute an effective tool for inverse designing of centrifugal pump, performance \& design sensitivity analysis \& optimization.

M. H. ShojaeeFard et al. [2006] have simulated the 3-d fluid flow of a centrifugal pump, but with viscous oils as Newtonian fluids. Head correction factor is found to be related to operating conditions. Pressure distribution over the suction $\&$ pressure side of the blade, when flow rate is the nominal one, is the best \& clearly appreciated.

Si Huang et al. [2006] have studied a multistage centrifugal pump with simulation $\&$ analysis in a commercial CFD software package using MRF technique, $\mathrm{k}-\varepsilon$ turbulence model. Performance is measured \& connected with $3 \mathrm{~d}$ flow field. Grid generation is done in GAMBIT and analysis in FLUENT with tetrahedron cell elements. Boundary conditions are mass flow inlet and at outlet, flow leakage takes place. A considerable interference of the velocity field at the impeller exit appears due to the interaction between impeller blades \& diffuser vanes.

Vlasak et al.(2007) investigated the pipeline transportation of fly ash slurry at volume concentrations in the range of $22 \%-31 \%$ and 
indicated that by adding bottom ash fractions the fly ash-bottom ash slurries reached slightly higher maximum concentration. He also revealed that a substantial reduction of the flow resistance can be achieved by addition of some drag reducing agents or by arrangements of particle size distributions or adopting some mechanical treatments. The flow behavior of the slurry was approximated by Yield-power law model. Since the addition of drag reducing agents causes a decrease of head loss therefore it is possible to use a lower operational velocity for the stabilized slurry, which brings a significant reduction in head loss. The effect of addition of Sodium hexameta-phosphate at $0.1 \%$ concentration (by weight) as an additive or rheological flow behavior of ash slurry was studied by Seshadri et al. (2008). By using the rheological data the head loss of fly ash slurry at high concentrations $\left(C_{W}=60 \%, 65 \%\right.$ and $68 \%$ ) were predicted using a Bingham plastic model. Since the additive modified the rheological behavior of the ash slurry a substantial reduction in head loss and energy consumption could be achieved.

A Benertam et al. [2007] showed the influence of solid particles on centrifugal pump having six impeller blades \& found that size and density like parameters etc. of the solid particles influences the head reduction factor and efficiency. The present work is done using well defined conditions, which are not universal and may not be true for all operating conditions. The correction factors generated in this paper vary with parameters like concentration, particle size/shape and mixture density. The material used for the pump is also derivable from these parameters. The study is quite effective if the operating conditions used for this work could be made more general.

L. Pullum et al.[2007] made a model for check and analysis of performance of centrifugal pump which conveys pastes/coarse solid particles. They introduced characteristic shear rate factors and proposed a model based on pump geometry, fluid rheology \& flow rate. The results show that moderate to high viscosity fluid generates a laminar flow. An overall equivalent viscosity is used with Hydraulic Institute Method to estimate viscous deration. Low flow rates with increased viscous deration prove the sensitivity of model. Head reduction is a function of coarse solid concentration.

Adnan Ozturk et al. [2008] studied the effect of impeller diffuser radial gap ratio in a centrifugal pump. For this purpose, they took a nontraditional centrifugal pump \&subjected its diffuser to different radial gaps with 15 different flow rates. Computational results are taken for static pressure, velocity vectors \& turbulent kinetic energy distribution at design volume flow rate at different radial gaps. K.E. drops as the radial gap increases. Decreasing gap ratio decreases pump efficiency also \& increases pressure fluctuations.

Mohammad F. Khalil et al. [2008] have studied that oil-in-water emulsion flow reduces the head and flow rate of the centrifugal pumps. As the holdup increase and temperature decrease, the reduction in head and flow rate increase. The change in the rheology of the emulsions with holdup, temperatures, and addition of surfactant is responsible for increasing the losses inside the pump and change in performance. Thus, the hydraulic efficiency decreases as the holdup increase and temperature decreases.

Krishnan V. Pagalthivarthi et al. [2003] have considered the effect of various operational and geometry conditions on these quantities VIZ. wall shear stresses, solid concentration along the wall and tangential velocity along the wall. Solid concentration and solid wall shear stress increase monotonically from the upstream of the tongue region to the downstream of the belly region. These quantities are crucial in wear calculations along the casing wall.

H Chen et al. [2010] analysed the reasons of low efficiency under different operation condition based on the performance test and CFD numerical simulation approach. Analysis focuses on the relationship between pump efficiency and inner flow characteristics. The study of the pump took a step forward when a gap drainage blade was proposed. The author proposed a new flow 
controlling method which not only improves the low specific speed pump performance but enriches and develops the centrifugal pump design theory.

Chung M K et al [2001] developed a simple and accurate correlation for the slip factor of centrifugal impeller. Correlation provided was a function of number of vanes, vanes exit angle \& the inlet-exit radius ratio. He investigated the radius of relative eddy inscribed by two adjacent vanes and the exit circle of a flow channel in the impeller to obtain the correlation.

Stephan Bross et al[2002] predicted the influence of different design parameters on the wear behaviour of centrifugal slurry pump's impeller suction sealing .For this purpose he developed a simple model and using this model he calculated the velocity field in the impeller suction side and also a comparison was done between analytical solution \& numerical solution provided by a CFD package FLUENT.

Egin and Gur [2003] have evaluated some existing correlations to predict head degradation of centrifugal slurry pumps. A new correlation has been developed in order to predict head reductions of centrifugal pumps when handling slurries. The proposed correlation takes into account the individual effects of particle. The proposed correlation is therefore recommended for the prediction of performance factors of "smallsized" slurry pumps having impeller diameters lower than $850 \mathrm{~mm}$ size, particle size distribution, specific gravity and concentration of solids, and impeller exit diameter on the pump performance.

\section{CONCLUSION:-}

A conventional centrifugal pump is designed to handle clear liquids. However when slurries are to be transported the conventional centrifugal pump has to be modified to handle solid liquid mixtures. The modifications incorporated in the pump include enlargement of flow passages to accommodate bigger solid particles, robust impeller with smaller number of vanes, special seals and proper material of construction to ensure longer life. Conventional design method of centrifugal pump are largely based on the application of empirical and semi-empirical rules along with the use of available information in the form of different types of charts and graphs as proposed by successful designers.

\section{REFERENCE:-}

1. Eric Dick, Jan Vierendeels, Sven Serbruyns and John Vande Voorde, (2001) "Performance prediction of centrifugal pumps with CFD tools". Task quarterly 5 No 4 (2001), 579-594, tq0405e7/580 26 I 2002 BOP s.c., http://www.bop.com.pl.

2. Jose' Gonza'lez, Joaquín Ferna'ndez, Eduardo Blanco Carlos Santolaria (2002) "Numerical Simulation of the Dynamic Effects Due to Impeller-Volute Interaction in a Centrifugal Pump". Vol. 124, JUNE 2002 Copyright (C) 2002 by ASME Transactions of the ASME

3. Weidong Zhou, Zhimei Zhao, T. S. Lee, and S. H.Winoto (2003) "Investigation of Flow Through Centrifugal Pump Impellers Using Computational Fluid Dynamics". International Journal of Rotating Machinery, 9(1): 49-61, 2003 Copyright ${ }^{\circ} \mathrm{c} 2003$ Taylor \& Francis 1023-621X/03 $\$ 12.00+.00$ DOI: $10.1080 / 10236210390147380$.

4. K M Guleren and A Pinarbasi (2004) "Numerical simulation of the stalled flow within a vaned centrifugal pump". Proc. Instn Mech. Engrs Vol. 218 Part C: J. Mechanical Engineering Science.

5. Miguel Asuajea, Farid Bakira, SmaÏne Kouidriła, Robert Reya (2004) “Inverse Design Method for Centrifugal Impellers and Comparison with Numerical Simulation Tools". International Journal of Computational Fluid. Dynamics, 18: 2, $101-110$.

6. G. R. Addie,A. Sellgren, (2005) “A First Slurry Pump Standard and some implications for paste systems."GIW Industries, USA, Lulea University of Technology, Sweden. 